\title{
Wisdom and Strategy - An Example for Zhang Liang and Liu Bang
}

\author{
Zhou Minhwa $^{*}$, Zhou Meihwa $^{2}$ \\ ${ }^{1}$ College of Literature, Huanggang Normal University, Huanggang, Hubei, China \\ ${ }^{2}$ College of Literature, Huanggang Normal University, Huanggang, Hubei, China \\ * Zhou Minhwa. Email: 2066348699@qq.com
}

\begin{abstract}
Liu Bang used to be just a County Magistrate (police station director) in Sishui County, Jiangsu Province. He had low status, no fighting experience, and no ability to defeat Xiang Yu, the God of war. But he was very lucky. Zhang Liang, a Han nobleman, was willing to be his counselor and always gave him good strategies so that he could defeat Xiang Yu and finally take the throne of emperor. Zhang Liang's best strategy for Liu Bang was to teach him to "bribe people's hearts, let the people of Qin Dynasty see his kindness, and they will hate Xiang Yu's cruelty. Zhang Liang didn't assist Liu Bang for a long time, but in seven years, Liu bang won the throne of emperor because of the support of the people. What are the ways Zhang Liang taught Liu Bang to "buy people's hearts"? Why does it work? All are the key issues to be explored in this paper.
\end{abstract}

Keywords: Shiji, Zhang Liang, Royal Preceptor(Dishi), Liu Bang, Proprieties and Law

\section{INTRODUCTION}

Liu Bang used to be just a pavilion chief (police station director) in Sishui County, Jiangsu Province. He had low status, no fighting experience, and no ability to defeat Xiang Yu, the God of war. But he was very lucky. Zhang Liang, a Han nobleman, was willing to be his counsellor and always gave him good strategies so that he could defeat Xiang $\mathrm{Yu}$ and finally take the throne of emperor. Zhang Liang's best strategy for Liu Bang was to teach him to "bribe people's hearts, let the people of Qin Dynasty see his kindness, and they will hate Xiang Yu's cruelty. Zhang Liang didn't assist Liu Bang for a long time, but in four years, Liu bang won the throne of emperor because of the support of the people. What are the ways Zhang Liang taught Liu Bang to "buy people's hearts"? Why does it work? All are the key issues to be explored in this paper.

\section{ZHANG LIANG TAUGHT LIU BANG TO BUY PEOPLE'S HEARTS THREE TIMES}

\subsection{Going South to Attack Wan}

In the third year of the second Qin Dynasty (207BC), King Huai of Chu agreed with everyone that the first one to enter Guanzhong was the King of Guanzhong.
However, King Huai of Chu asked Xiang Yu to go to the north to save Zhao. Only Liu bang led the army westward (Guanzhong was in the West). Liu Bang meets Zhang Liang in Qu. They captured more than ten Han cities occupied by the Qin Dynasty. Zhang Liang followed Liu Bang westward and became Liu Bang's counsellor. They first attacked Luoyang, then Wancheng to the south, ready to enter Wuguan.

But to enter Wuguan, you must pass Nanyang County first. Liu Bang fought with Lu Shi he, the governor of Nanyang Prefecture, who was defeated and retreated to Wancheng. Seeing that the gate of Wancheng was closed, Liu Bang wanted to move on to the west, but Zhang Liang thought it was not right, so he advised Liu Bang: "although you want to enter Guanzhong quickly, there are still a lot of troops in the state of Qin. If Wancheng is not attacked, it will form a front and back attack, which will be more dangerous。” [1] After hearing this, Liu Bang immediately changed the flag (he didn't want Lu Shi to find it), and came back from another road. The next morning, he completely surrounded Wancheng.

Seeing that Liu Bang suddenly came back to attack Wancheng, LV Shi Bi wanted to commit suicide. Chen Hui, his counsellor, immediately stopped him and went out to negotiate with Liu Bang. Chen Hui said to Liu Bang: Wancheng is the capital of Nanyang. There are 
dozens of cities with a large population and many materials. If the people of Wancheng come out to attack Liu Bang, Liu Bang must be very dangerous. Liu Bang simply let Wancheng surrender and let LV Shi continue to guard the city. Then he can take the army and materials of Wancheng and go west together(Figure 1). In western cities, if you see that Liu Bang did not kill LV Shi he, you will think that Liu Bang is benevolent and will also surrender to Liu Bang.

$$
\begin{array}{r}
\text { Pengcheng } \rightarrow \text { Changyi } \rightarrow \text { Gaoyang } \\
\rightarrow \text { Chenliu } \rightarrow \text { Kaifeng } \rightarrow \text { Baima } \rightarrow \text { Quyu } \\
\rightarrow \text { Yingyang } \rightarrow \text { Wuguan } \rightarrow \text { Lantian } \rightarrow \\
\text { Xiaoguan } \rightarrow \text { Bashang } \rightarrow \text { Xianyang. }
\end{array}
$$

Figure 1 Liu Bang's westbound route

Zhang Liang not only asked Liu Bang to agree with Chen Hui's proposal, but also asked Liu Bang to reward LV Shi and Chen Hui. Lu can continue to serve as a sheriff, and was also granted the title of Yin Hou. Chen Hui can collect taxes from 1000 households. In fact, Liu Bang does not have the right to reward LV Shi and Chen Hui at all. Zhang Liang deliberately asked Liu Bang to reward him in order to announce to the whole country that Liu Bang is already the king of Guanzhong. From then on, Liu Bang continued to move westward. Many counties and counties thought that Liu Bang was the king of Guanzhong, so they voluntarily opened the city gate and surrendered. Liu Bang could go westward without fighting.

Zhang Liang's plan was quite successful. Even Zhao Gao, the most powerful Eunuch in Xianyang City, sent someone to find Liu Bang, hoping that after he surrendered to Liu Bang, Liu Bang would give him half of the land in Guanzhong. Zhang Liang teaches Liu Bang to "buy people's hearts", but Fan Zeng, the counsellor of Xiang Yu (Liu Bang's opponent), lets Xiang Yu kill people cruelly and casually. Xiang Yu's army went to Xin'an and buried all the 200,000 Qin soldiers who surrendered to him alive. As we all know, Xiang $\mathrm{Yu}$ buried more than 200,000 Qin soldiers alive. He hated Xiang Yu very much and preferred Liu Bang. So going west, many people surrendered to Liu Bang. Zhang Liang taught Liu Bang to "buy off people's hearts", but Fan Zeng taught Xiang Yu to lose people's hearts. Although Liu Bang was not as good at fighting as Xiang Yu, he got everyone's support before he finally defeated Xiang Yu and became the emperor of Han Dynasty.

\subsection{Not living in Xianyang Palace}

After Liu Bang accepted the surrender of Qin's master Ziying, he entered Xianyang palace. Liu Bang was originally from Sishui, Peixian County, Jiangsu Province. He was born in a humble family. When he first entered the palace, he saw "so many treasures, so many beauties" and immediately had the idea of enjoying himself. He decided to live in Xianyang palace tonight. Fan Kuai immediately dissuaded: "does Peigong (Liu Bang) want to win the world or just want to be rich?" Liu Bang said: "the world." Fan Kuai said: "it was because of so many treasures and beauties that the Qin Dynasty perished. I hope you can move your army to hegemony instead of living in Xianyang palace. "

Fan Kuai is just a dog killer, no education at all, how can we say such a big truth? Qing Dynasty of Liang Yusheng he thinks: "It is speculated that this was written by the people of the Han Dynasty." [2] actually It's not written by Han Dynasty people, because After Fan Kuai have finished speaking, Zhang Liang persuaded Liu Bang at once: "Because the Qin Dynasty want to have fun, no benefits to the people. It's going to be the end of the country. Good medicine tastes bitter, but people don't want to listen, I hope you are willing to listen to Fan Kuai "

In fact, Zhang Liang and fan Kuai had the same idea. Liu Bang only wanted to have fun at that time. Zhang Liang knew it was hard to stop him, so he let fan Kuai persuade Liu Bang first. When fan Kuai finished, he would add that Liu Bang would not be angry and would be willing to accept advice. Liu Bang, 51, likes treasures and beauties very much, but he believes in Zhang Liang very much. As soon as Zhang Liang finished talking, he immediately ordered the army to retreat outside Hangu pass and stay in Bashang.

It is very important for Liu Bang to listen to Zhang Liang's advice and move his army to Bashang. Because if Liu Bang wants to be the king of Guanzhong, he must let the people in Guanzhong trust him. When Liu Bang entered Xianyang palace, he was not greedy for pleasure. The overlord people thought Liu Bang was a gentleman. Later, Liu Bang came to make an agreement with them, and they accepted it.

\section{MAKE A TREATY WITH THE PEOPLE IN GUANZHONG}

After Liu Bang retreated his army outside Hangu pass, he entered Guanzhong and made a treaty with the people in Guanzhong. He declared to the people, "the laws of the Qin Dynasty were too strict, and it was easy to commit capital crimes. Now that I'm the first one to enter Guanzhong and become the king of Guanzhong, I'm going to make three principles with you: only murder can be a capital crime, and both wounding and stealing should be judged according to the degree of injury. "

The people in Guanzhong are very happy because the laws of the Qin Dynasty were very strict, so it was easy to commit capital crimes. Now only killing people will be sentenced to death. Of course, they hope Liu Bang can 
become the king of Guanzhong. Liu Bang didn't read for many years, so he didn't understand this. Only Zhang Liang, a Han nobleman, knew the key to "let the people trust and accept".

Later, Liu Bang became emperor, many of whom were aristocrats in the Qin Dynasty, who had title and land and housing wealth. They refused to accept Liu Bang. Zhang Liang also taught Liu Bang to declare to them: "as long as people are willing to register registered residence and become Han people, you can inherit the title deed, land and house granted by Qin Dynasty. "[3] Those rich people registered residence with the Han Dynasty, and Liu Bang could get the support of the people. [4]

Fan Zeng didn't teach Xiang Yu to "buy people's hearts", nor did he tell Xiang Yu that he must be an emperor. He could not command the world if he was the "overlord of Western Chu". However, Zhang Liang taught Liu Bang not to be greedy for pleasure, but to reduce the penalty, and to keep the title and property of the rich in the Qin Dynasty. Fan Zeng's teaching made Xiang Yu lose his position, but Zhang Liang's teaching made people believe and like Liu Bang more. [5]

\section{CONCLUSION}

When the proprieties and laws of the pre-Qin Dynasty were completely destroyed, it was impossible to fight for morality. Liu Bang didn't know and didn't obey the etiquette. He just wanted to win. Zhang Liang is a Han nobleman. He knows the beauty of "proprieties and law" very well, so he uses it to buy people's hearts. Sure enough, his strategy is very successful. Liu Bang can not only avoid his weakest battle on his westward journey, but also enter Guanzhong quickly. [6]

Liu Bang could not have defeated Xiang Yu or become emperor of the Han Dynasty, but because of Zhang Liang's teaching, he could buy people's hearts at the most critical moment, so his image in the hearts of the people became more and more perfect. Only when there was a lack of troops and materials, there was no need to fight too much, and many Qin Dynasty sheriffs were willing to surrender voluntarily, Liu Bang could enter the country quickly Xianyang, also successfully became the king of Guanzhong.

When Liu Bang entered Xianyang palace and saw so many treasures and beauties, he was eager to enjoy himself. Only Zhang Liang can see the crisis after hedonism. Let fan Kuai dissuade Liu Bang first, and then he persuades Liu Bang, so that Liu Bang can completely restrain his desire and win the hearts of the people. Winning the hearts of the people is the most important key to Liu Bang's victory over Xiang $\mathrm{Yu}$, which is what Zhang Liang taught him and why Zhang Liang became the first emperor of the Han Dynasty.

\section{ACKNOWLEDGMENTS}

This paper is the phased achievements of the Doctoral Fund Project "Research on the original appearance and connotation of pre Qin etiquette and law" (2042020003) of Huanggang Normal University.

\section{REFERENCES}

[1] Sima Qian (145BC-?), Shiji, Zhonghua Book Company, Beijing.

[2] Liang Yusheng(1745-1819), Doubts about Shiji, Zhonghua Book Company, Beijing.

[3] Ban Gu (32-92), Hanshu, Zhonghua Book Company, Beijing.

[4] Lu Simian (1884-1957), History of Qin and Han Dynasties, Tianjin Social Science Press, Beijing.

[5] Qian Mu (1895-1990), History of Qin and Han Dynasties, Kyushu Publishing House, Beijing.

[6] Zhangjiashan Bamboo Slips sorting group, The Statutes and Ordinances of the Second Year, Cultural Relics Publishing Housey, Beijing. 